\title{
LÉVY-KHINTCHINE REPRESENTATION OF TOADER-QI MEAN
}

\author{
FENG QI AND BAI-Ni GUO
}

\begin{abstract}
In the paper, by virtue of a Lévy-Khintchine representation and an alternative integral representation for the weighted geometric mean, the authors establish a Lévy-Khintchine representation and an alternative integral representation for the Toader-Qi mean, verify that the Toader-Qi mean is a Bernstein function and that the divided difference of the Toader-Qi mean is a Stieltjes function, and collect a probabilistic interpretation and an application in engineering of the Toader-Qi mean.
\end{abstract}

Mathematics subject classification (2010): Primary 44A15, Secondary 26E60, 30E20, 33C10, 60G50. Keywords and phrases: Lévy-Khintchine representation, integral representation, Bernstein function, Stieltjes function, Toader-Qi mean, weighted geometric mean, Bessel function of the first kind, probabilistic interpretation, application in engineering, inequality.

\section{REFERENCES}

[1] Á. BeSENYEI, On complete monotonicity of some functions related to means, Math. Inequal. Appl. 16, 1 (2013), 233-239, available online at https ://doi .org/10.7153/mia-16-17.

[2] P. S. Bullen, Handbook of Means and Their Inequalities, Mathematics and its Applications, vol. 560, Kluwer Academic Publishers, Dordrecht-Boston-London, 2003.

[3] I. S. Gradshteyn and I. M. Ryzhik, Table of Integrals, Series, and Products, Translated from the Russian, Translation edited and with a preface by Daniel Zwillinger and Victor Moll, Eighth edition, Revised from the seventh edition, Elsevier/Academic Press, Amsterdam, 2015, available online at https://doi.org/10.1016/B978-0-12-384933-5.00013-8.

[4] B.-N. GUO AND F. QI, On the degree of the weighted geometric mean as a complete Bernstein function, Afr. Mat. 26, 7 (2015), 1253-1262, available online at http://dx.doi.org/10.1007/ s13370-014-0279-2.

[5] H. HARUKI, New characterizations of the arithmetic-geometric mean of Gauss and other well-known mean values, Publ. Math. Debrecen 38, 3-4 (1991), 323-332.

[6] H. Haruki And T. M. Rassias, New characterizations of some mean-values, J. Math. Anal. Appl. 202, 1 (1996), 333-348, available online at https://doi.org/10.1006/jmaa.1996.0319.

[7] M. Jeanblanc, M. Yor, And M. Chesney, Mathematical Methods for Financial Markets, Springer Finance. Springer-Verlag London, Ltd., London, 2009, available online at https://doi.org/10.1007/978-1-84628-737-4.

[8] G. E. Mog AND E. P. RIBEIRO, Mean and RMS calculations for sampled periodic signals with non-integer number of samples per period applied to AC energy systems, In: Congresso Ibero-LatinoAmericano de Métodos Computacionais em Engenharia-XXV Iberian Latin-American Congress on Computational Methods in Engineering, Recife, Pernambuco, Brazil, November 10-12, 2004.

[9] G. E. Mog AND E. P. Ribeiro, One cycle AC RMS calculations for power quality monitoring under frequency deviation, EEE Xplore (2004 11th International Conference on Harmonics and Quality of Power (IEEE Cat. No. 04EX951)) (2004), 700-705, available online at https://doi.org/10.1109/ICHQP. 2004.1409438.

[10] F. W. J. Olver, D. W. Lozier, R. F. Boisvert, and C. W. Clark (eds.), NiST Handbook of Mathematical Functions, Cambridge University Press, New York, 2010, available online at http://dlmf.nist.gov/. 
[11] F. QI, Bounding the difference and ratio between the weighted arithmetic and geometric means, Int. J. Anal. Appl. 13, 2 (2017), 132-135.

[12] F. QI, V. ČERŇANOVÁ, X.-T. SHI, AND B.-N. GuO, Some properties of central Delannoy numbers, J. Comput. Appl. Math. 328 (2018), 101-115, available online at https://doi.org/10.1016/ j.cam.2017.07.013.

[13] F. QI AND B.-N. GuO, The reciprocal of the geometric mean of many positive numbers is a Stieltjes transform, J. Comput. Appl. Math. 311 (2017), 165-170, available online at https://doi.org/ 10.1016/j. cam.2016.07.006.

[14] F. QI AND B.-N. GuO, The reciprocal of the weighted geometric mean is a Stieltjes function, Bol. Soc. Mat. Mex. (3) 23 (2017), in press, available online at https://doi.org/10.1007/ s40590-016-0151-5.

[15] F. QI AND B.-N. GUO, The reciprocal of the weighted geometric mean of many positive numbers is a Stieltjes function, Quaest. Math. 41 (2018), in press, available online at https://doi.org/ 10.2989/16073606.2017.1396508.

[16] F. QI AND D. LIM, Integral representations of bivariate complex geometric mean and their applications, J. Comput. Appl. Math. 330 (2018), 41-58, available online at https://doi.org/10.1016/j.cam.2017.08.005.

[17] F. QI, X.-T. ShI, AND B.-N. Guo, Some properties of the Schröder numbers, Indian J. Pure Appl Math. 47, 4 (2016), 717-732, available online at https://doi.org/10.1007/ s13226-016-0211-6.

[18] F. QI, X.-T. SHI, F.-F. LIU, AND Z.-H. YANG, A double inequality for an integral mean in terms of the exponential and logarithmic means, Period. Math. Hungar. 75, 2 (2017), 180-189, available online at https://doi.org/10.1007/s10998-016-0181-9.

[19] F. QI, X.-J. ZHANG, AND W.-H. LI, An integral representation for the weighted geometric mean and its applications, Acta Math. Sin. (Engl. Ser.) 30, 1 (2014), 61-68, available online at https://doi.org/10.1007/s10114-013-2547-8.

[20] F. QI, X.-J. ZHANG, AND W.-H. LI, Lévy-Khintchine representation of the geometric mean of many positive numbers and applications, Math. Inequal. Appl. 17, 2 (2014), 719-729, available online at https://doi.org/10.7153/mia-17-53.

[21] F. QI, X.-J. ZHANG, AND W.-H. LI, Lévy-Khintchine representations of the weighted geometric mean and the logarithmic mean, Mediterr. J. Math. 11, 2 (2014), 315-327, available online at https://doi.org/10.1007/s00009-013-0311-z.

[22] F. QI, X.-J. ZHANG, AND W.-H. LI, The harmonic and geometric means are Bernstein functions, Bol. Soc. Mat. Mex. (3) 23, 2 (2017), 713-736, available online at https://doi.org/10.1007/ s40590-016-0085-y.

[23] W.-M. Qian, X.-H. Zhang, And Y.-M. Chu, Sharp bounds for the Toader-Qi mean in terms of harmonic and geometric means, J. Math. Inequal. 11, 1 (2017), 121-127, available online at https://doi.org/10.7153/jmi-11-11.

[24] R. L. SChilling, R. SONG, AND Z. VondRaČEK, Bernstein Functions - Theory and Applications, 2nd ed., de Gruyter Studies in Mathematics 37, Walter de Gruyter, Berlin, Germany, 2012.

[25] G. ToAder, Some mean values related to the arithmetic-geometric mean, J. Math. Anal. Appl. 218, 2 (1998), 358-368, available online at https://doi.org/10.1006/jmaa.1997.5766.

[26] G. Toader And T. M. Rassias, New properties of some mean values, J. Math. Anal. Appl. 232, 2 (1999), 376-383, available online at https://doi.org/10.1006/jmaa.1999.6278.

[27] D. V. Widder, The Laplace Transform, Princeton Mathematical Series 6, Princeton University Press, Princeton, N. J., 1941.

[28] Z.-H. YANG AND Y.-M. CHU, A sharp lower bound for Toader-Qi mean with applications, J. Funct. Spaces 2016, Art. ID 4165601, 5 pages, available online at https://doi.org/10.1155/2016/ 4165601.

[29] Z.-H. YAng AND Y.-M. ChU, On approximating the modified Bessel function of the first kind and Toader-Qi mean, J. Inequal. Appl. 2016, 40 (2016), 21 pages, available online at https : //doi .org/ 10.1186/s13660-016-0988-1.

[30] Z.-H. YAng, Y.-M. ChU, AND Y.-Q. Song, Sharp bounds for Toader-Qi mean in terms of logarithmic and identric means, Math. Inequal. Appl. 19, 2 (2016), 721-730, available online at https://doi.org/10.7153/mia-19-52. 
Mathematical Inequalities \& Applications www.ele-math.com mialele-math.com 